THURSDAY, OCTOBER 9, I902.

\section{MENDEL'S THEORY OF HEREDITY.}

Mendel's Principles of Heredity: a Defence. By W. Bateson, M.A., F.R.S. With a Translation of Mendel's Original Papers on Hybridisation. Pp. xiv +212 . (Cambridge: University Press, I902.) Price 4s. net. Reports to the Evolution Committee of the Royal Society. Report I. Experiments undertaken by W. Bateson, F.R.S., and Miss E. R. Saunders. Pp. I6o. (London: Harrison, 1902.) Price Ios.

THERE can be no question of the importance, in reference to evolutionary theory, of a proper comprehension of the principles of heredity. Many attempts towards a solution of the problem have been made, but to none of them has it been possible hitherto to give more than a provisional approval. While the nature of this process remains unknown, the fabric of evolution cannot be regarded as in any sense complete. It seems certain that at present the question may be most hopefully approached from the statistical side, and to the labours of Galton and of Pearson we owe the enunciation of a law which gives quantitative expression to many of the observed facts. But about two years ago the discovery was made that Gregor Mendel, sometime Abbot of Brün, had long since, in the seclusion of his cloister, devised and carried through a very remarkable series of experiments in cross-fertilisation; and had on them based a theory which bids fair, if its truth can be established, to put the whole subject of heredity on an entirely new footing.

After more than thirty years of neglect, the Mendelian theory has found an energetic champion in Mr. Bateson, to whose lucid and exhaustive exposition of the doctrine in the two volumes before us students of the problem will naturally turn. Here we can only state in very briefest outline some of the main ccnclusions to which Mendel was led. In the instances (of pea-plants) selected by him for experiment, it was found that when two plants, differing in a given feature, were crossed, the hybrid offspring invariably exhibited one of the parental characters (called by Mendel the "dominant") to the entire or partial exclusion of the other (called "recessive"). After self-fertilisation, each hybrid prodnced offspring in which the two antagonistic parental characters (Bateson's " allelomorphs"), dominant and recessive, appeared in a ratio closely approximating on an average to $3: \mathrm{I}$. Further experiment showed that while the recessive minority henceforth bred true, the other class consisted of one-third genuine dominants also breeding true, and two-thirds "cross-breds" (Bateson's "heterozygotes"), which latter on self-fertilisation again gave the old ratio of $3: \mathrm{I}$, and so on. When plants differing in several characters instead of one only were taken, mutatis mutandis the same law was found to hold good. From these and other experiments, ingeniously devised and giving wonderfully accordant results, Mendel was led to formulate the hypothesis of the numerical equality in kinds, and purity in respect of given characters, of the gametes produced by any zygote, whatever the composition of the latter. The No. I7 I9, voL. 66] consequences of the acceptance of this view would undoubtedly be far-reaching, and Mr. Bateson does well, in reprinting a translation of Mendel's original papers and also in recording the illustrative experiments made by himself and Miss E. R. Saunders, to trace out in considerable detail the main lines of speculation thus laid open.

The chief issue between the Mendelian and Galtonian conceptions is the question of " ancestral " heredity ; and in disallowing the latter $\mathrm{Mr}$. Bateson is pitting himself against a formidable triumvirate. Prof. Weldon has discussed Mendel's results from this point of view in a critical, but, as it seems to us, not unfriendly spirit. Much may be conceded to the zeal of an advocate, but we regret certain personalities in Mr. Bateson's "Defence." An impartial judge, after hearing the able statements of counsel, would probably desire to adjourn the case for the production of further evidence.

On p. 7 I of the first-named work, $A b a b$ should read $A b+a b$, and similarly $a B a b$ should be $a B+a b$. Giltay's name appears in the bibliography as "Gitay."

F.A. D.

\section{LIGHTNING ARRESTORS IN ELECTRICAL ENGINEERING.}

Die Schutzvorrichtungen der Starkstromtechnik gegen atmosphärische Entladungen. By Dr. Gustav Benischke. (Brunswick : Friedr. Vieweg und Sohn.) T $T$ is customary in Germany to divide electrical 1 engineering into two parts, the "Starkstrom" and "Schwachstrom"-the "strong" and "weak" current branches. This book is the first issue of a series, edited by Dr. Benischke, each issue to be complete in itself and to deal with some application of the industry. The first issue treats of the means adopted in the "strong current" branch, i.e. electric lighting and power, for protection against atmospheric electrical discharges With overhead lines, especially overhead power-transmission lines, this subject is one of great importance, and is also one upon which very little is known with certainty. It is interesting to find that the author, on the first page, gives it as his opinion that it is impossible to protect a line against the effects of being directly struck by lightning. In such a case a destruction of the insulation is bound to take place. It is well that electrical engineers should understand this, and be clear in their own minds that the so-called lightning arrestors at present on the market afford no protection here. Fortunately, such cases are very rare. Protection is afforded, according to Dr. Benischke, by lightning arrestors against the weaker side discharges which accompany the main lightning flash, also against spark discharges due to the static charges which the overhead conductors assume as the result of dust, snow, \&c., and against induced discharges caused by atmospheric electrical disturbances in the neighbourhood.

The book contains a very clear and concise description of the various forms of lightning arrestors at present in use. Nearly all of them consist of spark gaps placed with one side of the gap connected to the conductor and the other side to earth. Should, therefore, at any time the conductor become charged to a high potential, a B B 